\title{
HOW SUCCESSFUL IS CORNEAL TRANSPLANTATION? A REPORT FROM THE AUSTRALIAN CORNEAL GRAFT REGISTER
}

\author{
KERYN A. WILLIAMS, SYLVIA M. MUEHLBERG, ROWENA F. LEWIS \\ and DOUGLAS J. COSTER \\ on behalf of all contributors to the Australian Corneal Graft Registry (ACGR)
}

\begin{abstract}
SUMMARY
Corneal graft outcome was assessed within a large, prospectively collected database of 4499 records. Penetrating corneal graft survival was $91 \%$ at 1 year, $72 \%$ at 5 years and $69 \%$ at 7 years. The three most common indications for graft were keratoconus $(30 \%)$, bullous keratopathy (25\%) and failed previous graft $(18 \%)$; the three most common causes of graft failure were rejection $(34 \%)$, infection $(18 \%)$ and glaucoma $(9 \%)$. The vast majority of grafts were performed for improved visual acuity. About four-fifths of recipients achieved at least one line of better acuity on the Snellen chart post-operatively; of the remainder with unchanged or worse acuity, only $21 \%$ had failed grafts. Overall, $43 \%$ of recipients achieved a best corrected Snellen acuity of $6 / 12$ or better, $52 \%$ achieved $6 / 18$ or better, and $20 \%$ had acuitities of less than $6 / 60$. Reasons for poor post-operative acuity (recorded as less than $6 / 60$ ) included graft failure $(41 \%)$ and comorbidities in the grafted eye $(43 \%)$. A number of risk factors for graft failure were examined: in most instances, there was little room for decision-making or expert intervention.
\end{abstract}

No single yardstick is available to measure the success of corneal transplantation. Amongst the outcomes that need to be considered (depending upon the circumstances) are graft survival, visual outcome, relief of pain, adequacy of structural repair, improved cosmesis, appropriateness of the procedure and the patients' perceptions of the final result. An additional layer of complexity is furnished by the dynamic nature of measures of outcome: at what

From: Department of Ophthalmology, Flinders University of South Australia, Adelaide, South Australia, Australia.

Correspondence to: $\mathrm{Dr}$ K. A. Williams, Department of Ophthalmology, Flinders Medical Centre, Bedford Park, SA 5042, Australia. time-point post-operatively should a given measure be applied? Third, some consideration needs to be given to an assessment of whether a given outcome is actually amenable to change by expert intervention.

Clearly, any discussion of outcomes is best anchored in baseline data, one source of which is the general case register. Research databases provide information that is qualitatively and quantitatively different from the data that accrue from clinical trials and the two approaches are complementary. A database allows long-term and continuing assessment of current outcomes, which in turn may provide the impetus for clinical trials. Here, we examine factors affecting corneal graft and visual outcome within such a large register, to try to address the question of the success of corneal transplantation.

\section{PATIENTS AND METHODS}

The register operates within the guidelines of the institutional Committee on Clinical Investigations. No experimentation on human subjects is involved. Entry and follow-up of corneal graft recipients into the register and statistical analyses were described elsewhere. $^{1,2}$ In brief, data were mailed to the Registry by the contributing surgeon as soon as possible after the graft and follow-up information was requested at approximately yearly intervals. Missing data were routinely sought by follow-up letter. Each graft was followed until graft failure or until the death or loss to follow-up of the patient. Snellen acuities and keratometry readings were compared using the Mann-Whitney U-test, adjusted for ties (Minitab v8, Minitab Inc., State College, PA, USA). Kaplan-Meier survival functions were prepared using SPIDA (Statistical Laboratory, Macquarie University, NSW, Australia).

Prospectively collected data entered by 
approximately 300 contributors were available on 6031 penetrating corneal grafts, $4499(75 \%)$ of which had been followed. Minimum trial time was 1 day (representing primary non-functions), maximum trial time was 7.7 years; 170 recipients $(4 \%$ of those followed) had died and $504(11 \%)$ had been lost to follow-up.

Presenting diseases, indications for graft, postoperative complications and reasons for graft failure were coded using the ICD.9.CM system (US Department of Health and Human Services). The intraocular pressure (IOP) was generally considered to be significantly raised if a reading of $25 \mathrm{mmHg}$ or greater was made by applanation tonometry, but the decision was at the discretion of the ophthalmologist. Primary graft non-functions were defined as grafts that never thinned and cleared in the post-operative period. The trial time for such grafts was arbitrarily adjusted to 1 day. Any existing graft that was replaced by another in the same eye, irrespective of graft clarity and for whatever reason, was classified as a failed graft. In other cases, graft failure was defined as oedema and irremediable loss of clarity in a previously thin, clear graft. The day of failure was the first day the patient was seen with an oedematous, opaque graft that subsequently failed to thin and clear. Rejection was defined as the development of a rejection line (epithelial or endothelial) or a unilateral anterior chamber reaction with corneal infiltrates and spreading corneal oedema in a previously thin, clear graft. Any development with the potential to compromise graft outcome was considered to be a complication. Information was specifically sought on complications including exposed sutures, stitch abscess, breakage/premature loosening of graft suture, retained suture material, wound dehiscence, neovascularisation of the graft, synechiae, uveitis, rise in IOP, fixed dilated pupil, cataract, rejection episode, microbial keratitis, herpetic recurrence, early changes of bullous keratopathy, refractive and related errors, and factors potentially affecting visual outcome but unrelated to the graft (including cataract, aphakia, amblyopia, retinal detachment, cystoid macular oedema and senile macular degeneration). Contributors were asked to specify any other relevant complications, information or departures from their preferred treatment, and operative procedures on the grafted eye including refractive surgery. They also provided data on refraction, acuity and lens status.

For Kaplan-Meier survival curves, ${ }^{3-5}$ trial time was calculated as the number of days between the date of graft and the date on which the patient was last seen. For failed grafts, trial time was calculated as the number of days between the date of graft and the date of failure. Cox proportional hazards regression was used to investigate associations between potential risk factors and the risk of graft failure. ${ }^{6}$

\section{RESULTS}

\section{Overall Graft Survival}

Overall Kaplan-Meier survival of penetrating grafts followed within the ACGR is shown in Fig. 1. Graft survival at $1,3,5$ and 7 years was $91 \%, 79 \%, 72 \%$ and $69 \%$, respectively. The major indications for graft were keratoconus (30\%), pseudophakic and aphakic bullous keratopathy $(25 \%)$, failed previous graft $(18 \%)$, corneal scars and opacities $(11 \%)$ and corneal dystrophies (7\%). Major reasons for the 640 cases of graft failure are listed in Table I: irreversible rejection was the most important cause of graft failure, followed by infective complications (including herpetic recurrences) and glaucoma. It is noteworthy that in 194 cases $(30 \%)$, the reasons for graft failure were considered to be multifactorial. An earlier study ${ }^{2}$ encompassing about half the grafts that have now been followed showed near-identical indications for graft and major reasons for failure, suggestive of a reasonably stable pattern of practice over some years. Analysis of Cox proportional hazards regression of factors influencing graft outcome at the earlier time indicated that wound dehiscence, a rise in IOP after graft, inflammation at the time of graft, an indication for graft that was not keratoconus or a corneal dystrophy, a history of previous graft in the ipsilateral eye, a graft size outside the range of $7.0-7.9 \mathrm{~mm}$ diameter, and the

Table I. Reasons for the failure of penetrating corneal grafts

\begin{tabular}{lcr}
\hline Cause of failure & Number & $(\%)$ \\
\hline Irreversible rejection & $219^{\mathrm{a}}$ & 34 \\
Infections & $112^{\mathrm{b}}$ & 18 \\
Glaucoma & $58^{\mathrm{c}}$ & 9 \\
Primary non-functions & 36 & 6 \\
Trauma & 24 & 4 \\
Corneal ulcers & $16^{\mathrm{d}}$ & 2 \\
Pseudophakic bullous keratopathy & 15 & 2 \\
Other, specified causes & $76^{\mathrm{e}}$ & 12 \\
Corneal oedema/decompensation & 55 & 9 \\
Unknown & 41 & 6 \\
& - & - \\
& 640 & 100 \\
\hline
\end{tabular}

a Includes 9 with glaucoma, 3 with abscesses, 2 with cyclitic membranes, 1 adenovirus iritis.

${ }^{b}$ Includes 26 with herpes simplex virus (HSV) recurrence, 11 with HSV and rejection, 2 with herpes zoster ophthalmicus, 38 with abscesses, 17 with endophthalmitis, 9 with infective corneal perforations, 7 with fungal keratitis and 2 with Acanthamoeba keratitis.

${ }^{c}$ Includes 2 with abscesses, 2 with abnormal corneal membranes, 1 each with unspecified keratitis, uveitis, retinal detachment, epithelial calcification, epithelial downgrowth, wound leak, peripheral anterior synechiae, neovascularisation, pseudophakic touch.

d Includes 2 with rheumatoid arthritis, 2 with dry eyes, 1 with Stevens-Johnson syndrome.

${ }^{\mathrm{e}}$ Eight epithelial defects, 7 rheumatoid arthritis, 7 non-infective perforations, 7 phthisis bulbi, 4 retinal detachments, 3 aphakic bullous keratopathy, 1 each striate keratitis, corneal ectasis, astigmatism. 
PROBABILITY OF GRAFT SURVIVAL

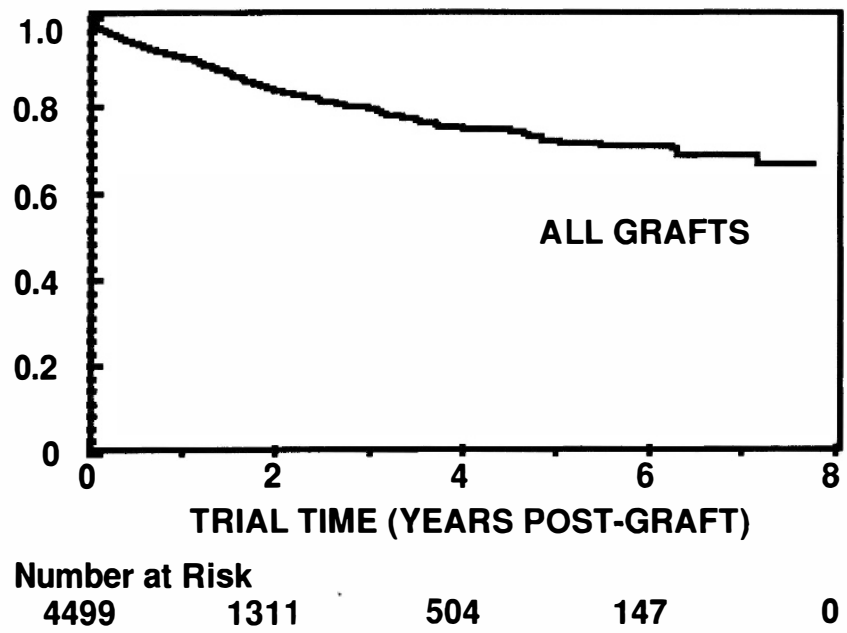

Fig. 1. Kaplan-Meier curve of graft survival for all penetrating corneal grafts followed within the Australian Corneal Graft Registrv.

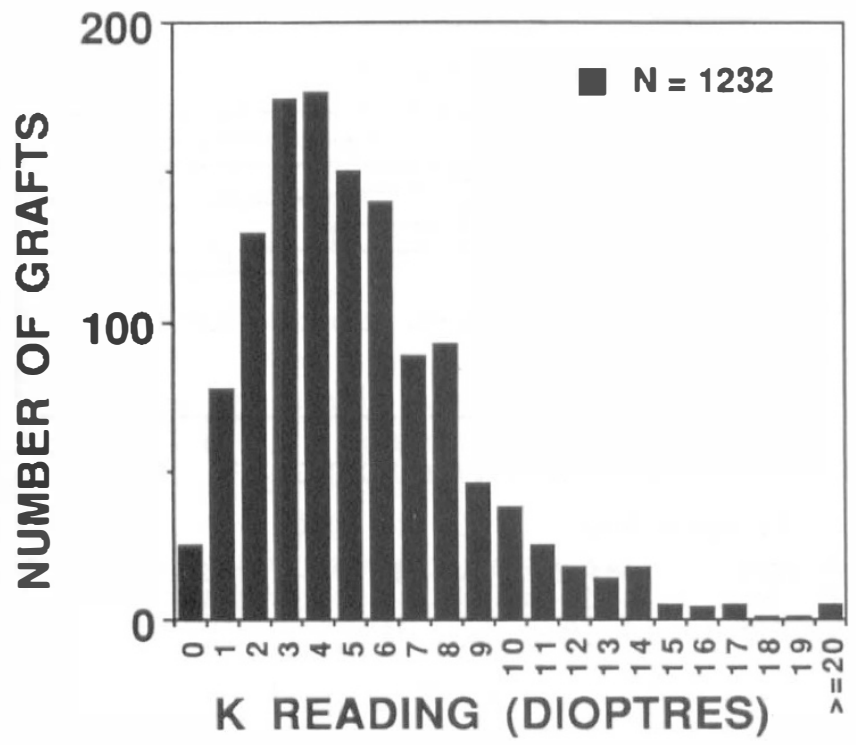

Fig. 3. Post-operative astigmatism as measured by keratometry at most recent follow-up for penetrating corneal grafts. $K$ readings were available for $27 \%$ of those grafts followed.

\section{PROBABILITY OF GRAFT SURVIVAL}

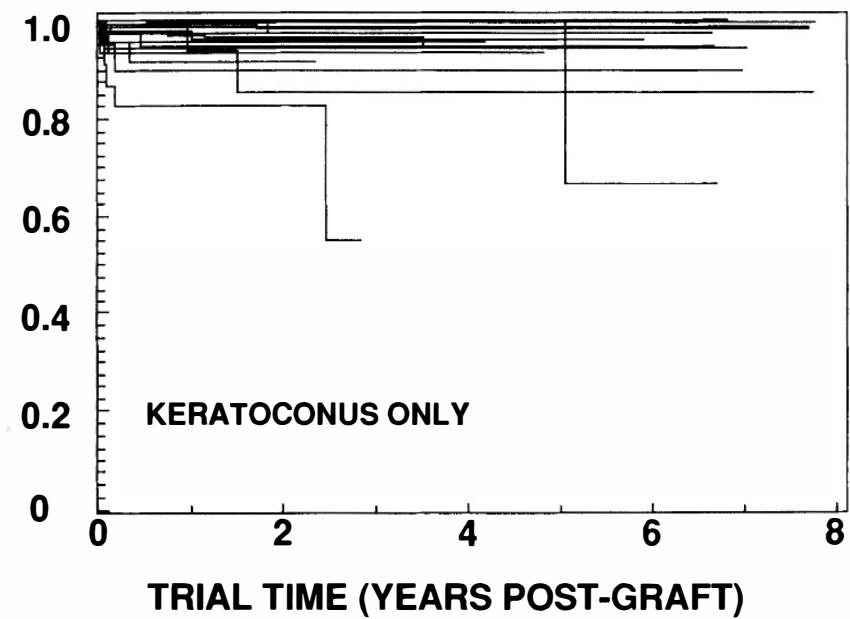

(a)

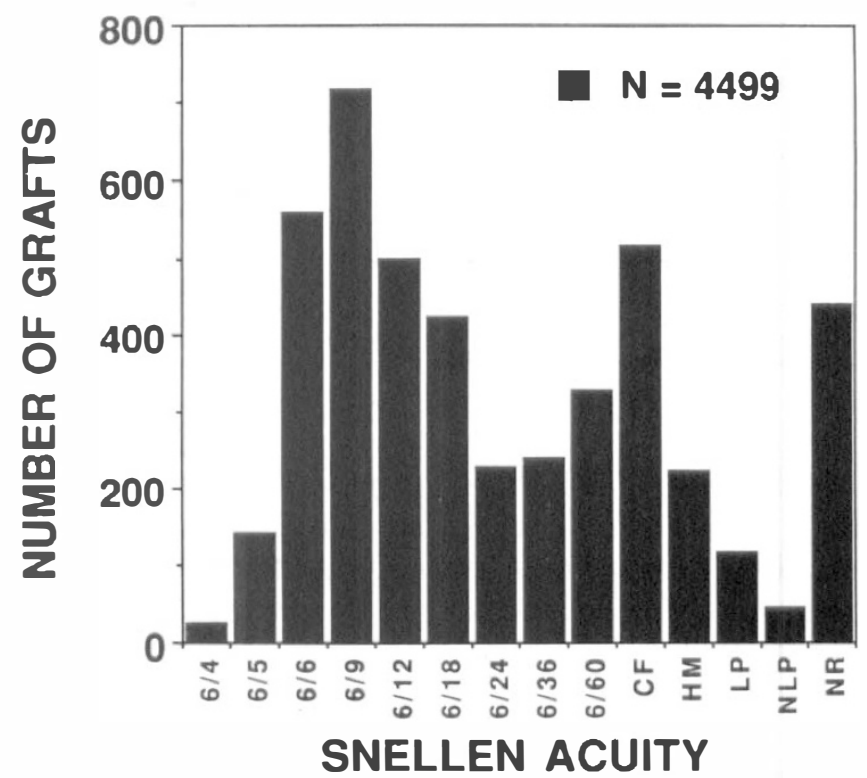

Fig. 2. Best corrected Snellen acuity at the time of most recent follow-up for all penetrating corneal grafts. $C F$, count fingers at $3 \mathrm{~m}$; HM, hand movements; LP, light perception; NLP, no light perception; $N R$, not recorded. Of those for whom acuity was not recorded, 204 of 441 grafts (46\%) had failed.

PROBABILITY OF GRAFT SURVIVAL

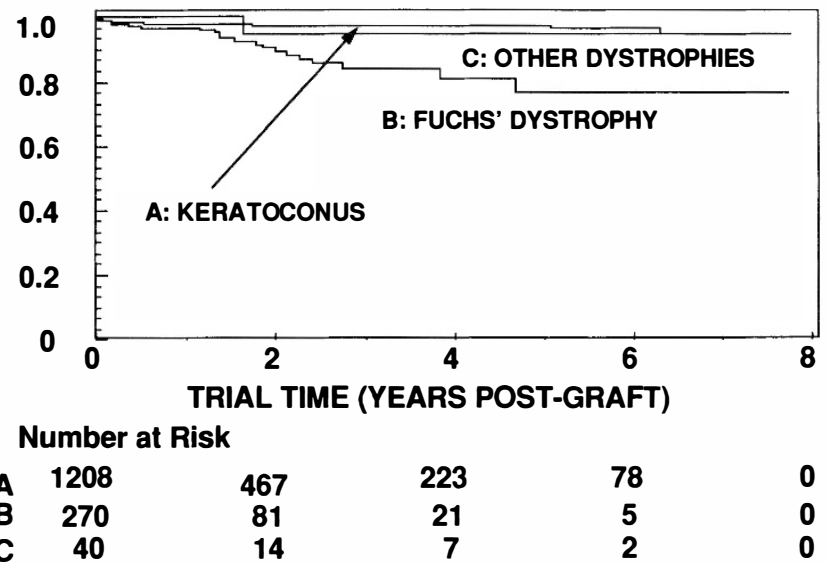

Fig. 4. Survival of grafts for keratoconus, Fuchs' dystrophy and other corneal dystrophies. The stratum of other dystrophies includes 9 lattice, 8 granular, 8 posterior polymorphous, 7 macular, 5 anterior, 2 juvenile, 1 crystalline dystrophy.

\section{PROBABILITY OF GRAFT SURVIVAL}

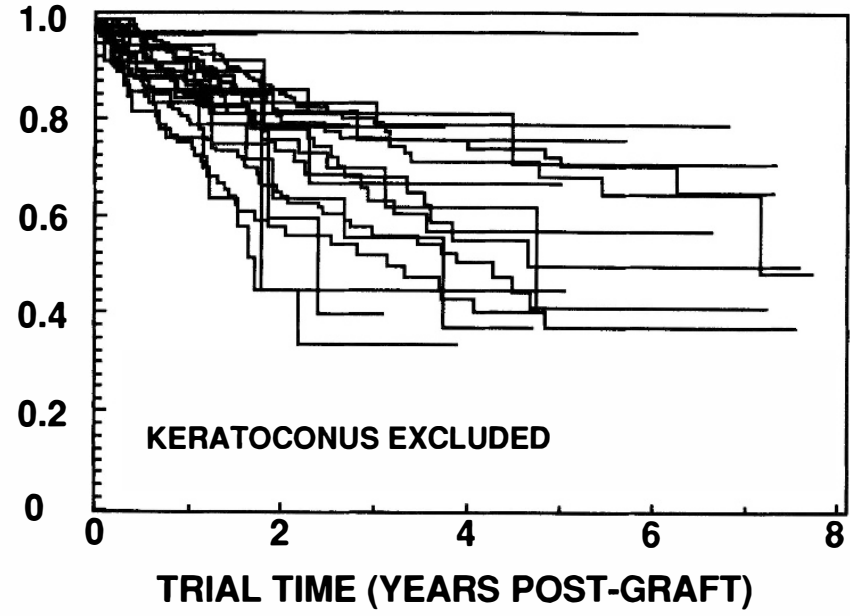

(b)

Fig. 5. Centre effect (20 individual contributors contributing most records with follow-up) stratified according to indication for graft: (a) keratoconus $(\mathrm{p}=0.00003)$ or $(b)$ any reason except keratoconus $(\mathrm{p}<0.00001)$. 
PROBABILITY OF GRAFT SURVIVAL

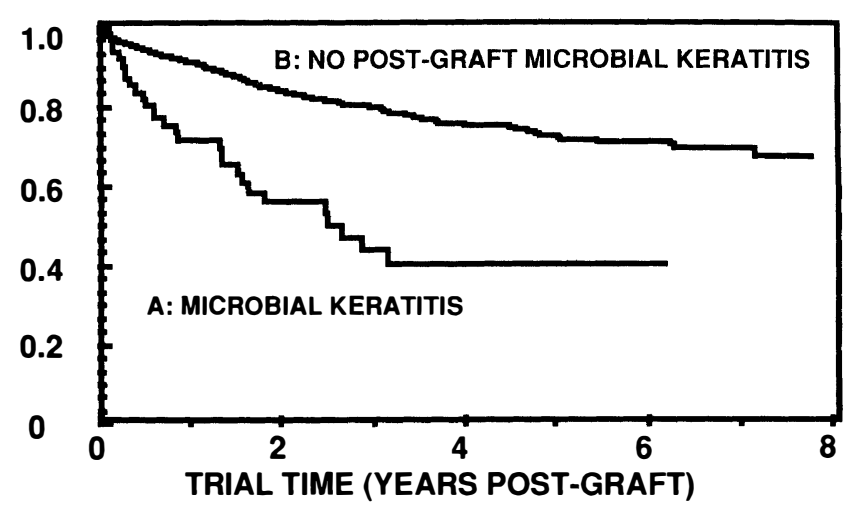

Number at Risk

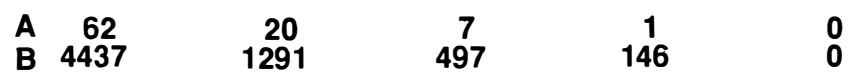

Fig. 6. Influence of $\geqslant 1$ episode of microbial keratitis in the post-operative period $(\mathrm{p}<0.00001)$.

PROBABILITY OF GRAFT SURVIVAL

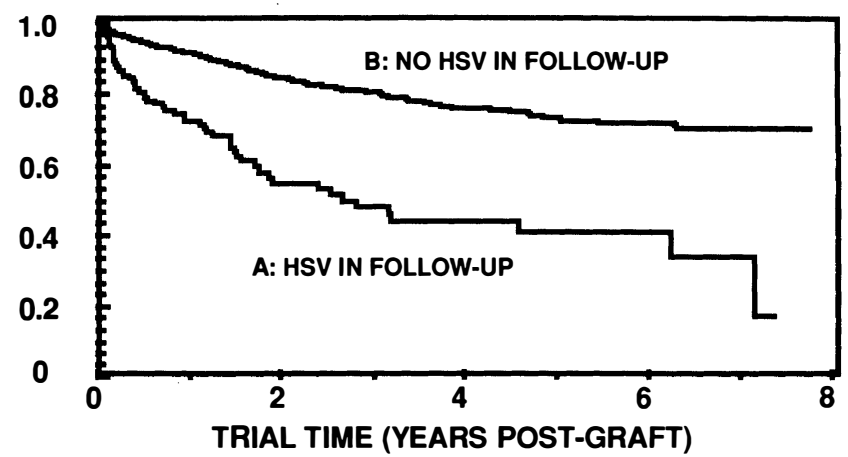

Number at Risk

$\begin{array}{lrr}\text { A } & 115 & 39 \\ \text { B } & 4384 & 127\end{array}$

(a)
PROBABILITY OF GRAFT SURVIVAL

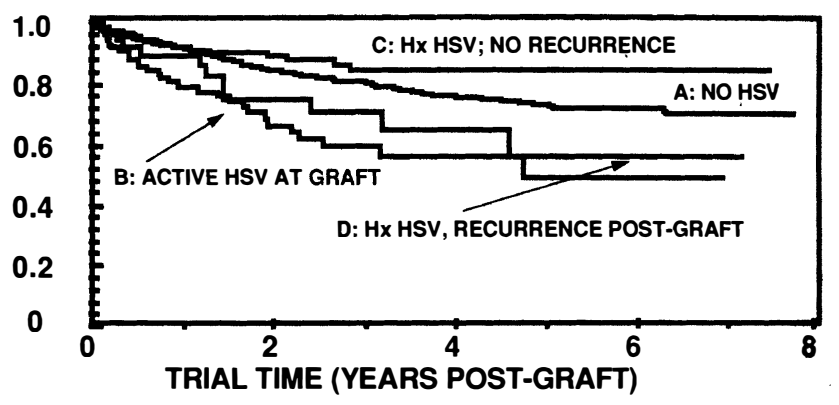

Number at Risk

$\begin{array}{lrrrrr}\text { A } & 4085 & 1172 & 446 & 133 & 0 \\ \text { B } & 88 & 32 & 12 & 3 & 0 \\ \text { C } & 224 & 75 & 34 & 5 & 0 \\ \text { D } & 37 & 17 & 7 & 3 & 0\end{array}$

(b)

Fig. 7. Influence of $(a) \geqslant$ episode of herpes simplex virus $(H S V)$ infection after graft $(\mathrm{p}<0.00001)$ and $(b)$ active herpetic disease at graft, history of $(H x)$ herpetic disease in the past with and without post-graft recurrence, and no history of HSV before or after graft $(\mathrm{p}<0.00001)$.

\section{PROBABILITY OF GRAFT SURVIVAL}

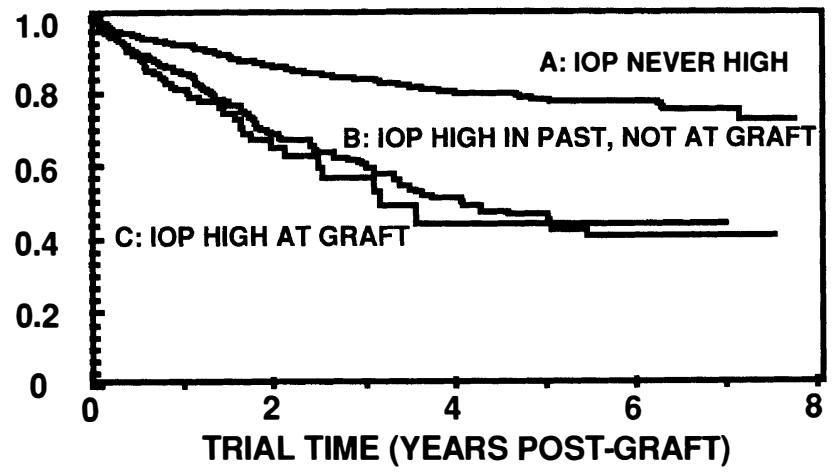

Number at Risk
PROBABILITY OF GRAFT SURVIVAL

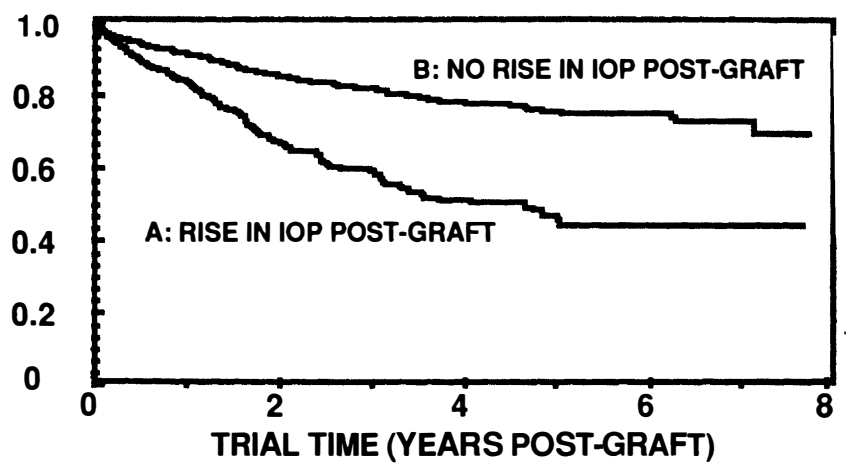

Number at Risk

$\begin{array}{ll}\text { A } 445 & 147 \\ \text { B } 4054 & 1164\end{array}$

59
445

15
132

(b)

(a)

Fig. 8. Influence of (a) history of raised intraocular pressure (IOP) before and at the time of graft $(\mathrm{p}<0.00001)$ and $(b)$ a rise in IOP in the post-operative period $(\mathrm{p}<0.00001)$. 
Table II. Reasons for poor post-operative Snellen acuity $(<6 / 60)$ after corneal transplantation

\begin{tabular}{lcc}
\hline Reason & Number & $(\%)$ \\
\hline Failed graft & 371 & 41 \\
Co-morbidity in the grafted eye & $390^{\mathrm{a}}$ & 43 \\
Complication of graft & $74^{\mathrm{b}}$ & 8 \\
Not refracted & $29^{\mathrm{c}}$ & 3 \\
No clear cause for poor acuity & $35^{\mathrm{d}}$ & 5 \\
& 899 & - \\
\hline
\end{tabular}

${ }^{a}$ Fifty glaucoma, 30 cataract, 19 amblyopia, 27 aphakia, 65 cystoid macular oedema, 21 retinal detachment, 73 other retinal disorder, 24 vitreoretinal disorder, 3 anisometropia, 8 miscellaneous, 70 mixture of different problems.

b Twenty-eight major astigmatism, 14 rejection, 6 corneal scar, 4 abscess, 4 dry eye, 3 corneal degeneration, 2 Gunderson flap, 13 miscellaneous.

'Assessed from contributors' comments on the forms. Follow-up times were very variable. In 17 cases, it was considered too early to refract.

${ }^{d}$ In these cases, the entire record was reviewed by two people and no indication of the likely problem could be identified.

presence of an anterior chamber intraocular lens or aphakia in the grafted eye were independent risk factors for graft failure. ${ }^{2}$

\section{Visual Outcome}

Snellen Acuity and Astigmatism Post-graft. Snellen acuities for the whole cohort with follow-up are shown in Fig. 2; the pattern did not alter noticeably when only grafts followed for longer than 2 years were examined (data not shown). Overall, $43 \%$ of recipients achieved a best corrected Snellen acuity of $6 / 12$ or better, $52 \%$ achieved $6 / 18$ or better, and $20 \%$ had acuities of less than 6/60. Significant anisometropia was listed as a problem in $1 \%$ of recipients. Reasons for poor post-operative acuity (recorded as less than 6/60) are shown in Table II: as might have been anticipated, graft failures and other complications of the graft accounted for about $50 \%$ of cases, but a substantial proportion (over $40 \%$ ) of recipients

Table III. Immediate reasons for graft

\begin{tabular}{lrr}
\hline Reason for graft & Number & $(\%)$ \\
\hline Improved visual acuity only & 2411 & 78 \\
+ pain & 325 & 11 \\
+ tectonic & 27 & 1 \\
+ cosmesis & 20 & 1 \\
+ pain + tectonic & 5 & $<1$ \\
+ pain + cosmesis & 12 & $<1$ \\
+ tectonic + cosmesis & 2 & $<1$ \\
+ pain + tectonic + cosmesis & 1 & $<1$ \\
Pain only & 200 & 6 \\
+ tectonic & 7 & $<1$ \\
+ cosmesis & 2 & $<1$ \\
Tectonic only & 65 & 2 \\
Cosmesis only & 12 & $<1$ \\
& - & - \\
& 3089 & 100 \\
Total for improved visual acuity & 2803 & \\
Total for pain & 552 & \\
Total for tectonic repair & 107 & \\
Total for improved cosmesis & 49 & \\
\hline
\end{tabular}

Table IV. Pre- and post-operative Snellen acuity

\begin{tabular}{lrr}
\hline Visual outcome after graft & Number & $(\%)$ \\
\hline Number of recipients for whom information available & 1594 & 35 \\
Snellen acuity same before and after graft & 193 & 12 \\
Snellen acuity worse after graft & 143 & 9 \\
Snellen acuity better after graft & 1258 & 79 \\
\hline
\end{tabular}

had a co-morbidity in the grafted eye that reduced the visual potential of that eye.

Post-operative astigmatism as measured by keratometry is shown in Fig. 3. Keratometry readings were available for 1232 grafts $(27 \%$ of those followed); the median post-graft astigmatism was 5 dioptres (range, $0->20$ dioptres). One or more refractive surgical procedure had been performed on 290 grafts $(6 \%)$ followed, including suture adjustment or selective removal $(32 \%)$, insertion of compression sutures $(21 \%)$, relaxing incisions and $\mathrm{T}$ cuts $(48 \%)$, wedge resections $(4 \%)$, radial keratotomy $(1 \%)$, and other refractive keratectomy including by excimer laser ( $9 \%$ ).

Immediate Reasons for Graft and Comparison of Preand Post-operative Acuity. Contributors to the register were requested to nominate the immediate reasons for graft. The vast majority of grafts were performed to improve visual acuity, with a small but significant number performed for the relief of pain (Table III); in about $14 \%$ of instances, immediate reasons for graft were multifactorial. Grafts for structural repair of the globe and for improved cosmesis were relatively rare.

In $35 \%$ of cases followed, information was available on best corrected Snellen acuity in the grafted eye, both immediately prior to the graft, and again at the time of the most recent post-operative visit (Table IV). About four-fifths (79\%) of recipients achieved at least one line of better acuity on the Snellen chart post-operatively; of the remainder with

Table V. Comparison strata of patients with failed and surviving grafts, for whom elevated IOP had been recorded post-graft

\begin{tabular}{lcc}
\hline & \multicolumn{2}{c}{ Graft outcome } \\
\cline { 2 - 3 } Factor & Failed (\%) & Surviving (\%) \\
\hline Phakic & 13 & 19 \\
Aphakic & 35 & 17 \\
Pseudophakic & $46^{\mathrm{a}}$ & $62^{\mathrm{b}}$ \\
Medication for raised IOP & 53 & 75 \\
Glaucoma procedure & $26^{\mathrm{c}}$ & $16^{\mathrm{d}}$ \\
\hline
\end{tabular}

${ }^{a}$ Forty-three per cent posterior chamber IOL, $43 \%$ anterior chamber IOL, $3 \%$ sutured posterior chamber IOL, $10 \%$ irisfixated anterior chamber IOL

b Fifty-six per cent posterior chamber IOL, $24 \%$ anterior chamber IOL, $16 \%$ sutured posterior chamber IOL, $4 \%$ irisfixated anterior chamber IOL

${ }^{c}$ Thirty-six per cent Molteno implant, 33\% trabeculectomy, 6\% cyclocryotherapy, $25 \%$ unspecified.

${ }^{\mathrm{d}}$ Forty-three per cent trabeculectomy, 20\% Molteno implant, $6 \%$ cyclocryotherapy, $4 \%$ photocoagulation, $4 \%$ iridectomy, $2 \%$ cyclodialysis, $20 \%$ unspecified. 
PROBABILITY OF GRAFT SURVIVAL

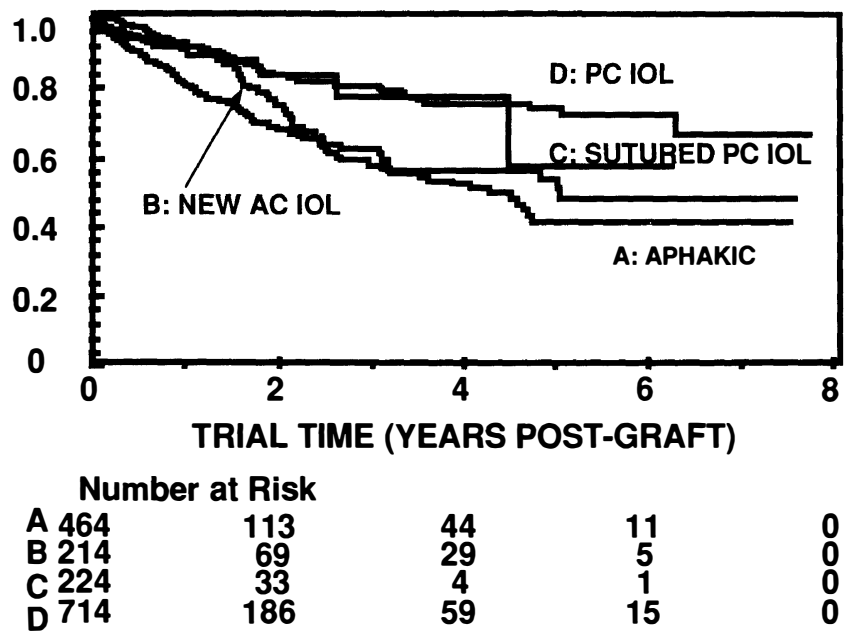

Fig. 9. Influence of lens status on corneal graft survival in aphakic recipients, recipients with a sutured posterior chamber (PC) intraocular lens (IOL), recipients of a modern anterior chamber (AC) IOL (defined as a lens inserted at the time of graft or after graft) and, for comparative purposes, those with an unsutured PC IOL $(\mathrm{p}<0.00001)$.

unchanged or worse acuity, $21 \%$ had failed grafts. For the relatively small numbers for whom information was available, $83 \%$ of those grafted only to improve visual outcome showed some improvement, compared with $70 \%$ and $63 \%$ of those grafted only for pain relief or structural repair, respectively.

\section{Specific Indications for Graft and Causes of Graft Failure}

Keratoconus and Corneal Dystrophies: The Centre Effect. Patients grafted for keratoconus, Fuchs' dystrophy or one of the corneal dystrophies (9 lattice, 8 granular, 8 posterior polymorphous, 7 macular, 5 anterior, 2 juvenile, 1 crystalline) did well post-operatively (Fig. 4), although it is worth noting that survival in the very small substratum $(n=8)$ of patients with posterior polymorphous dystrophy ( $80 \%$ at 5 years) was more akin to the survival rate for Fuchs' dystrophy ( $76 \%$ at 5 years) than for keratoconus ( $97 \%$ at 5 years). Graft survival as a function of individual contributor has always shown great variation within the database, ${ }^{1,2}$ a reflection to some extent of the varying indications for graft within individual practices. Survival curves stratified for keratoconus or for other indications for graft for the 20 ophthalmologists contributing the largest numbers (range 41-499) of records with follow-up to the register are shown in Fig. 5a and 5 b: the curves are tightly clustered for keratoconus (although there are significant differences in outcome, $p=0.00003$ ), but show enormous variation when other indications for graft are considered $(p<0.00001)$.

Infections. After irreversible rejection, the sequelae of infections (including bacterial, fungal and viral infections, and clinical entities such as endophthalmitis, suppurative keratitis, corneal abscesses including stitch abscesses, and herpetic recurrences) were the most important reasons for graft failure. Of the cohort followed, $1 \%$ had suffered at least one episode of bacterial or fungal keratitis post-graft, and $3 \%$ had had a herpetic episode in the grafted eye. Graft survival for the former group is shown in Fig. 6: perhaps not surprisingly, outcome was poor $(p<0.00001)$ and infection was listed as the cause of graft failure in $45 \%$ of the grafts that had failed. The situation with respect to herpetic disease was more complex. Kaplan-Meier survival for those with a herpetic episode post-operatively (Fig. 7a) was $41 \%$ at 5 years, compared with $73 \%$ in those who have not suffered such an episode $(p<0.00001): 55$ of 115 such grafts had failed, the majority $(80 \%)$ from the sequelae of the recurrence itself, often complicated by graft rejection. Outcome for those with active herpetic disease at the time of graft, and for those with a past history of herpetic disease but without active disease at graft, is shown in Fig. 7b $(p<0.00001)$. It seems clear that the predisposing event for failure in those without active disease at graft was actually the post-operative recurrence.

Raised IOP. Glaucoma was the third most commonly listed cause of graft failure within the database. In univariate analysis, a history of raised IOP prior to graft and high IOP at graft $(p<0.00001)$ and a rise in IOP in the follow-up period $(p<0.00001)$ were all significant risk factors for graft failure (Fig. 8a, b). In those with a post-operative rise in IOP, a past history of elevated IOP had been recorded in $44 \%$. A comparison of some facets of the stratum with elevated IOP in the follow-up, and with either failed or surviving grafts, is shown in Table V: of relevance may be the observation that less than $20 \%$ of grafts in either stratum were phakic, compared with $50 \%$ in either the total cohort followed or in the stratum without a post-operative rise in IOP.

Lens status. One of the risk factors for graft failure over which the ophthalmologist has some control is lens status. Immediately prior to corneal transplantation, $60 \%$ of recipients were phakic, $30 \%$ were pseudophakic and $10 \%$ were aphakic; immediately after graft, the figures were $49 \%, 41 \%$ and $11 \%$, respectively. These changes reflect intracapsular and extracapsular cataract extractions, and intraocular lens (IOL) insertions, removals and exchanges.

We have previously shown graft survival to be significantly poorer in pseudophakic (any lens position) and aphakic recipients than in phakic recipients, and recipients with anterior chamber IOLs (considering recently inserted and long-standing lenses together) or anterior chamber iris-fixated lenses showed poorer graft survival than recipients 
Table VI. Visual outcome and complications associated with differing lens status and procedures in corneal graft recipients

\begin{tabular}{lccccccc}
\hline \multirow{2}{*}{$\begin{array}{l}\text { Post-operative } \\
\text { lens status }\end{array}$} & $\begin{array}{c}\text { No. } \\
\text { followed }\end{array}$ & $\geqslant 6 / 12$ & $\geqslant 6 / 18$ & $<6 / 60$ & \begin{tabular}{c} 
Best corrected Snellen acuity (\%) \\
\cline { 3 - 5 } detachment $^{\text {a }}(\%)$
\end{tabular} & $\begin{array}{c}\text { Cystoid macular } \\
\text { oedema (\%) }\end{array}$ & $\begin{array}{c}\text { Other vitreoretinal } \\
\text { degeneration or disease (\%) }\end{array}$ \\
\hline PC IOL & 714 & 31 & 43 & 20 & 1 & 15 & 14 \\
Sutured PC IOL & 224 & 17 & 29 & 38 & 4 & 30 & 22 \\
Modern AC IOL & 214 & 21 & 31 & 30 & 4 & 33 & 17 \\
Aphakic & 464 & 16 & 25 & 44 & 7 & 15 & 12 \\
Triple procedure & 429 & 40 & 55 & 14 & 0 & 13 & 12 \\
Staged procedure & 84 & 46 & 58 & 6 & 0 & 10 & 5 \\
\hline
\end{tabular}

PC, posterior chamber.

${ }^{a}$ Occurring since the time of graft.

${ }^{b}$ Modern AC, modern anterior chamber inserted at or after graft, not iris-fixated.

with a posterior chamber lens. ${ }^{7:}$ Graft outcome in aphakic recipients, recipients with a sutured posterior chamber IOL, recipients of a modern anterior chamber IOL (defined as a lens inserted at the time of graft or after graft) and, for comparative purposes, in those with an unsutured posterior chamber lens is shown in Fig. 9. Separate comparisons indicated no significant differences in graft survival between eyes with a posterior chamber or a sutured posterior chamber lens $(p=0.89)$, or in eyes with a sutured posterior chamber lens or a modern anterior chamber lens $(p=0.434)$, although graft survival was higher in the former group. However, aphakic patients did show significantly worse graft survival than those with a modern anterior chamber lens $(p=0.022)$ or a sutured posterior chamber lens $(p=0.0012)$.

We have found no differences in overall visual outcome (as measured by Snellen acuity) between recipients with sutured posterior chamber IOLs or modern anterior chamber IOLs $(p=0.459)$, but aphakic patients had poorer Snellen acuities than those with a sutured posterior chamber IOL $(p=0.0031)$ or a modern anterior chamber IOL $(p=0.0007)$. However, there may have been less cystoid macular oedema in the aphakic patients (Table VI).

No difference in graft survival $(p=0.995), \mathrm{K}$ readings $(p=0.371)$ or overall Snellen acuity $(p=0.479)$ was apparent between recipients who had undergone a triple procedure, as compared with a staged procedure. Anisometropia in the two groups was $1.4 \%$ and $1.2 \%$, respectively.

\section{DISCUSSION}

Comparison of Corneal Graft Survival with Survival of Other Types of Graft

Within the large, multicentre series, 1 year and 5 year Kaplan-Meier graft survival in a cohort of 4499 corneal allografts was $91 \%$ and $72 \%$. For comparison, survival of renal allografts in several large studies has been reported as $81-86 \%$ at 1 year ${ }^{8.9}$ and $62 \%$ at 5 years, ${ }^{9}$ and of liver recipients (not grafts) as $79 \%$ at 1 year and $69 \%$ at 5 years. ${ }^{10}$ Interestingly, the survival of most vascularised organ grafts has shown a very considerable improvement over the last 10-20 years: $^{9-11}$ renal graft survival in one large series, for example, improved from $54 \%$ at 5 years in 1971 to $82 \%$ in $1986 .{ }^{9}$ Results of liver transplantation have improved from a 1 year patient survival of $10 \%$ prior to 1975 , to $77 \%$ in $1992^{11}$ largely because of increased graft survival; such improvements are widely believed to reflect improvements in management and, in particular, improved immunosuppression.

It is difficult to establish whether corneal graft survival has improved at the same rate over the same time-frame, because there are relatively few early papers which provide Kaplan-Meier survival curve analysis of graft outcome. One such is the seminal early work of Batchelor and colleagues in 1976, ${ }^{12}$ who reported 1 year survival of $57 \%$ and 2 year survival of $50 \%$ in a cohort of 200 cases, all of which were HLA typed. Any apparent improvement in survival rates may, however, be illusory: the 1976 cohort included a relatively high number of high-risk cases, of which $40 \%$ were regrafts and $71 \%$ had evidence of corneal vascularisation at graft, compared with an $18 \%$ regraft rate and $35 \%$ with evidence of vascularisation in our own series.

One obvious difference between the practice of corneal transplantation and that of essential organ transplantation over the past 20 years is that those immunosuppressive agents (including cyclosporin A and FK506) that have revolutionised the outcome of the latter have not thus far found a place in corneal transplantation. Systemic cyclosporin A does improve corneal graft outcome, ${ }^{33}$ but may be associated with substantial risks to the recipients in the long term: conventional immunosuppressive drugs appear to increase incidence of neoplasia if given over many years, ${ }^{14}$ and it is not clear how long systemic immunosuppression would have to be maintained for corneal transplantation. Most practitioners use topical corticosteroids to reduce the incidence of corneal allograft rejection. ${ }^{15}$ Topical cyclosporin A is almost certainly less effective than are topical corticosteroids, probably because of the 
extremely hydrophobic nature of the drug. Systemic $^{16}$ and local ${ }^{17}$ admininstration of FK506 look promising in animal models of penetrating keratoplasty, but have yet to be tested clinically.

\section{Prospects for Expert Intervention to Alter Graft Outcome}

Graft survival is very dependent upon the initial indication for graft and there are a limited number of areas where positive intervention or appropriate decision-making by the ophthalmologist can affect outcome. In this context, it is appropriate to emphasise that one relevant decision is whether to perform the graft in the first place. Patient satisfaction post-operatively is correlated with graft survival and achievement of a better visual acuity in the graft than in the contralateral eye, ${ }^{18}$ and in cases other than keratoconus or corneal dystrophy it may be preferable not to undertake surgery if there is good existing vision in the other eye. The spread of results obtained by individual surgeons is probably a partial reflection of acceptance of differing sets of indications for graft. The rates of corneal transplantation per head of population vary widely in different countries ${ }^{19}$ not all the variation reflects inadequate donor supply. Thus, for example, approximately the same number of corneal grafts per year are performed in Australia as in the United Kingdom, but the latter has about three times the population of the former. A high graft rate may not always be correlated with good outcome.

Of the three most commonly reported reasons for graft failure - specifically, rejection, infection and glaucoma - there may be little that the ophthalmologist can do, once the graft has been performed, other than to treat any complications promptly. However, for the subset of recipients with a history of herpes simplex virus infection, the use of prophylactic systemic acyclovir, ${ }^{20}$ or possibly topical acyclovir, ${ }^{21}$ to reduce the incidence of recurrences clearly merits consideration, given that herpetic recurrence is so strongly associated with graft failure in this and other studies. ${ }^{21}$

Control of lens status in corneal graft recipients may be one area where deliberate decision-making is possible. Insertion of an unsutured posterior chamber lens is clearly the procedure of choice after cataract extraction, but where this is not possible, the decision as to whether to insert a sutured posterior chamber lens, a flexible loop anterior chamber lens or to leave the eye aphakic, is more difficult. As a group, aphakic patients exhibit significantly poorer graft survival and Snellen acuity than do those with a sutured posterior chamber or modern anterior chamber lens, but may suffer less cystoid macular oedema. Iris-fixated anterior chamber lenses are associated with very poor graft survival. The prevalence of cystoid macular oedema observed in grafted eyes with a sutured posterior chamber lens in this series was higher than that reported in a smaller cohort elsewhere, ${ }^{22}$ and approximately the same as in others studies. ${ }^{23,24}$ Schein and colleagues ${ }^{25}$ have recently suggested that better results are obtained with iris fixation of posterior chamber implants compared with transscleral fixation in patients with corneal grafts: we are unable to compare their results with our own data, because we did not collect information on the method of fixation of these implants.

\section{Why Measure Outcome?}

Amongst the transplantation community at large, corneal transplantation continues to maintain an enviable reputation for success. Whether this reputation is entirely warranted is, perhaps, questionable. Continuous assessment of the actualities of graft and visual outcome after corneal transplantation is plainly of more than academic interest. Should such outcomes be invariably excellent, then a disinterested observer might reasonably ask whether scarce research resources might not more profitably be transferred to other branches of ophthalmic practice, or to other areas of transplantation. Should such outcomes be less than perfect (as is of course the case in virtually all of medical practice), then a disinterested observer might wish to investigate the extent and nature of the problems, on the basis that such information should allow the accurate and ethical counselling of patients prior to graft, the identification of cases in which latitude for alternative approaches to clinical decision-making exists, and the prioritisation of future research efforts.

\section{How Successful is Corneal Transplantation?}

In answer to the question 'How successful is corneal transplantation?', we can say that in a large cohort of patients, grafted for a wide variety of indications by a large number of ophthalmologists operating under different circumstances, the 5 year graft survival will be approximately $70 \%$. Half the recipients are likely to achieve good best corrected Snellen acuity from their graft (and about four-fifths will show at least one line of improvement on the Snellen chart), whereas 1 in 5 will achieve less than 6/60. The median degree of post-operative astigmatism is 5 dioptres. For the $20 \%$ of patients who see poorly, approximately half will have a failed graft or will have suffered a complication of the graft, whilst $40 \%$ will have an unrelated co-morbidity in the grafted eye. Many of the co-morbidities affecting visual potential will have been present but unrecognised before graft, because the posterior segment was unable to be visualised adequately in the presence of corneal opacity. Bearing in mind that at least $78 \%$ of 
grafts are performed primarily for improved visual acuity and that for a further $14 \%$ improved acuity is one of multiple reasons for graft, the level of comorbidities in the cohort is a serious problem influencing outcome for the patient. Whereas graft outcome in some subgroups of patients is truly excellent when measured by any yardstick, this is not the case in a substantial number of others.

A subset of the data presented in Table VI have been presented elsewhere in preliminary form.

The authors wish to thank all ophthalmologists who contribute information to the ACGR, and Dr George Wong for critical review of the manuscript. This work was supported by the NH\&MRC, the Lions Eye Care and Research Foundation and AHMAC.

Key words: Corneal transplantation, Graft failure, Registry, Visual outcome.

\section{REFERENCES}

1. Williams KA, Roder D, Esterman A, Muehlberg SM, Coster DJ. Factors predictive of corneal graft survival: report from the Australian Corneal Graft Registry. Ophthalmology 1992;99:403-14.

2. Williams KA, Muehlberg SM, Win SJ, Coster DJ on behalf of all contributors. The Australian Corneal Graft Registry, 1990-1992 report. Aust NZ J Ophthalmol 1993;21 (Suppl): 1-48.

3. Kaplan EL, Meier P. Nonparametric estimation from incomplete observations. J Am Stat Assoc 1958; 53:475-81

4. Peto R, Pike MC, Armitage P, Breslow NE, Cox DR, Howard SV, et al. Design and analysis of randomised clinical trials requiring prolonged observation of each patient. I. Introduction and design. $\mathrm{Br} \mathrm{J}$ Cancer 1976;34:585-612.

5. Peto R, Pike MC, Armitage P, Breslow NE, Cox DR, Howard SV, et al. Design and analysis of randomised clinical trials requiring prolonged observation of each patient. II. Analysis and examples. $\mathrm{Br} \mathrm{J}$ Cancer 1977;35:1-39.

6. Cox DR. Regression models and life tables. J R Stat Soc [Ser B] 1972;34:187-220.

7. Williams KA, Muehlberg SM, Lewis RF, Coster DJ on behalf of all contributors to the Australian Corneal Graft Registry (ACGR). Influence of lens status on graft and visual outcome within a corneal graft register. Transplant Proc (in press).

8. Opelz G for the Collaborative Transplant Study. Superior long-term kidney graft survival in patients on maintenance immunosuppression with cyclosporine and azathioprine. Transplant Proc 1993;25:1289-90.

9. Landais P, Jais JP, Margreiter R, Tufveson G, Brunner F, Selwood N, Mallick N. Modelling long-term survival in 52315 first cadaveric grafts: the European experience. Transplant Proc 1993;25:1316-7.
10. Kilpe VE, Krakauer H, Wren RE. An analysis of liver transplant experience from 37 transplant centres as reported to Medicare. Transplantation 1993;56:554-61.

11. Jamieson NV, Friend PJ, Johnston PS, Alexander G, Barnes ND, Calne RY. Twenty-four years of orthotopic liver transplantation at Addenbrooke's Hospital, Cambridge. Transplant Proc 1993;25:1102-4.

12. Batchelor JR, Casey TA, Gibbs DC, Lloyd DF, Werb A, Prasad SS, James A. HLA matching and corneal grafting. Lancet 1976;1:551-4.

13. Hill JC. The use of cyclosporine in high-risk keratoplasty. Am J Ophthalmol 1989;107:506-10.

14. Sheil AGR, Disney APS, Mathew TH, Amiss N, Excell L. Cancer development in cadaveric donor renal allograft recipients treated with azathioprine (AZA) or cyclosporine (CyA) or AZA/CyA. Transplant Proc 1991;23:1111-2.

15. Rinne JR, Stulting RD. Current practices in the prevention and treatment of corneal graft rejection. Cornea 1992;11:326-8.

16. Nishi M, Herbort CP, Matsubara M, Morishita Y, Nishimura $\mathbf{M}$, Nieda $\mathbf{M}$, et al. Effects of the immunosuppressant FK506 on a penetrating keratoplasty rejection model in the rat. Invest Ophthalmol Vis Sci 1993;34:2477-86.

17. Kobayashi C, Kanai A, Nakajima A, Okumura K. Suppression of corneal graft rejection in rabbits by a new immunosuppressive agent, FK-506. Transplant Proc 1989;21:3156-8.

18. Williams KA, Ash JK, Pararajasegaram P, Harris S, Coster DJ. Long-term outcome after corneal transplantation: visual result and patient perception of success. Ophthalmology 1991;98:651-7.

19. Coster DJ, Williams KA. Donor cornea procurement: some special problems in Asia. Asia-Pacific J Ophthalmol 1992;4:7-12.

20. Foster CS, Barney NP. Systemic acyclovir and penetrating keratoplasty for herpes simplex keratitis. Doc Ophthalmol 1992;80:363-9.

21. Moyes AL, Sugar A, Musch DC, Barnes RD. Antiviral therapy after penetrating keratoplasty for herpes simplex keratitis. Arch Ophthalmol 1994;112:601-7.

22. Holland EJ, Daya SM, Evangelista A, Ketcham JM, Lubniewski AJ, Doughman DJ, Lane SS. Penetrating keratoplasty and transscleral fixation of posterior chamber lens. Am J Ophthalmol 1992;114:182-7.

23. Hill JC. Transscerally-fixated posterior chamber intraocular implants without capsular support in penetrating keratoplasty. Ophthalmic Surg 1992;23:320-4.

24. Hassan TC, Soong HK, Sugar A, Meyer RF. Implantation of Kelman-style, open-loop anterior chamber lenses during keratoplasty for aphakic and pseudophakic bullous keratopathy: a comparison with irissutured posterior chamber lenses. Ophthalmology 1991;98:875-80.

25. Schein OD, Kenyon KR, Steinert RF, Verdier DD, Waring GO III, Stamler JF, et al. A randomised trial of intraocular lens fixation techniques with penetrating keratoplasty. Ophthalmology 1993;100:1437-43. 